\title{
Sistemas de Proteção Contra Quedas com Cabo de Segurança na Construção'
}

\author{
Marcelo Fabiano Costella \\ Emanuela Rizzotto \\ Letícia Nonennmacher
}

\section{Introdução}

Sabe-se que a construção civil é responsável por um grande número de acidentes e mortes de trabalhadores, sendo a queda de altura o principal problema enfrentado em obras de diferentes países (BRANCHTEIN, et al., 2015).

Fatalidades desse tipo ocorrem principalmente devido à falta de proteção adequada ou à deficiência dos sistemas utilizados, condicionados, segundo Borjan et al. (2016), pelo comportamento dos empregadores, a indisponibilidade de equipamentos e o tamanho da empresa.

Referente aos empregadores, Cherri e Argudin (2016) explicam que tais responsáveis pela contratação e gestão de pessoal ainda apresentam certa dificuldade em tratar do tema. Consequentemente, os colaboradores são submetidos a tarefas em altura sem que possuam experiência, sem aprender métodos de trabalho e receber equipamentos de proteção adequados (EVANOFF et al., 2016).

1 Versão resumida do artigo publicado na Revista SODEBRAS, v. 11, n. 128 de Agosto de 2016, nas páginas 133 a 140, pelos mesmos autores. 
Dentre os equipamentos de uso obrigatório em qualquer atividade executada a partir de 2,0 metros de altura, com risco de queda, tais como telhados, estruturas e coberturas, estão os cintos de segurança, conforme a NR 18 - Condições e Meio Ambiente de Trabalho na Indústria da Construção (BRASIL, 2016). Entretanto, ainda que normas regulamentadoras do trabalho em altura estejam em vigor, como a já citada NR 18 Condições e Meio Ambiente de Trabalho na Indústria da Construção (BRASIL, 2016) e a NR 35 - Trabalho em Altura (BRASIL, 2014), é grande o número de problemas envolvendo a má qualidade do planejamento, aplicação e controle dos sistemas de proteção. Um dos possíveis fatores contribuintes diz respeito à maneira como as normas abordam os requisitos de desempenho, não incorporando pontos relevantes, como eficiência e flexibilidade, além da falta de especificações quanto à forma de avaliar seu uso.

Desta forma, é necessário desenvolver métodos e materiais que auxiliem na análise da utilização dos sistemas de segurança contra quedas, fazendo com que os requisitos atualmente estabelecidos também contemplem questões práticas do dia a dia da obra e proporcionem sistemas mais seguros e práticos.

Com o foco de proporcionar uma visão mais ampla dos requisitos necessários ao eficaz projeto e aplicação de cabos de segurança, bem como à análise de conformidades para utilização, este estudo pretende apontar níveis de atendimento a requisitos de segurança, eficiência e flexibilidade.

\section{Método}

\subsection{Delineamento da Pesquisa}

A presente pesquisa consistiu na elaboração de um protocolo de avaliação de desempenho de cabos de segurança. Um teste do protocolo é apresentado com base na sua aplicação em obras da cidade de Chapecó, Santa Catarina.

Foi realizado o levantamento e estudo de requisitos importantes para a avaliação de diversos cabos usados na proteção dos trabalhadores da construção civil com base nas categorias de segurança, contemplando-se questões de projeto e operação, de eficiência e flexibilidade.

\subsection{Identificação dos Requisitos}

Para identificação dos requisitos foram utilizadas as normas brasileiras NR 18 Condições e Meio Ambiente de Trabalho na Indústria da Construção (BRASIL, 2016) e NR 35 - Trabalho em Altura (BRASIL, 2014), bem como as normas inglesas OSHA 1926.501 (OCCUPATIONAL..., 1996a), OSHA 1926.502 (OCCUPATIONAL..., 1996b) e OSHA 1926.503 (OCCUPATIONAL..., 1996c). Além disso, a identificação dos requisitos teve como fundamento as disposições recomendadas pelos sistemas de proteção 
periférica (SPP), propostos no protocolo elaborado por Peñaloza et al. (2015), bem como falhas observadas a partir do acompanhamento de atividades que utilizavam cabos de segurança nas obras selecionadas.

Dessa forma, foram identificados 30 requisitos para compor o protocolo, distribuídos da seguinte forma: 5 requisitos referem-se à segurança na etapa de projeto, 12 requisitos referem-se à segurança na etapa de operação; 7 requisitos referem-se à eficiência e 6 referem-se à flexibilidade.

\subsection{Níveis de Atendimento}

Com os requisitos definidos, identificados e devidamente separados por categoria, foi elaborado o protocolo para avaliação do cabo de segurança. O responsável por responder ao protocolo pode escolher entre as seguintes opções, para cada requisito: SIM, se a situação analisada atendesse totalmente o requisito; NÃO, caso o requisito não fosse atendido na obra; PARCIALMENTE quando a situação da obra atendia parcialmente o requisito; e NÃO SE APLICA, caso o requisito não fosse aplicável às características da obra. Para analisar os dados e interpretar os resultados, foi atribuída uma pontuação para cada resposta, da seguinte forma: SIM, 100\%; NÃO 0\%; PARCIALMENTE 50\%. Caso a resposta seja NÃO SE APLICA, ela não será considerada.

\subsection{Seleção das Obras e Coleta de Dados}

Como meio de efetivar a pesquisa, foram definidos sete canteiros de obras da cidade catarinense para realização de visitas. Escolhidos os locais, foi caracterizado o sistema de cabo de segurança utilizado na obra, identificando-se o material utilizado nos cabos, a forma de fixação e os cuidados tomados com o sistema. A Tabela 1 apresenta as características dos sistemas utilizados em cada obra. Foi observado ainda qual era o profissional responsável pela segurança do trabalho presente na obra, seja o técnico de segurança, o engenheiro de segurança do trabalho ou, na maioria dos casos, o próprio engenheiro civil responsável pela execução da obra.

Foram coletados os dados nos canteiros de obras através de aplicação do protocolo de avaliação, verificando-se todos os requisitos para o sistema de cabo de segurança. Nesta etapa, as questões foram respondidas pelo profissional responsável por fiscalizar a obra, junto ao cabo de segurança instalado, o que permitiu também a observação direta do sistema. O local avaliado foi sempre o último pavimento, observado em sua totalidade, no qual o cabo de segurança estava instalado. Por fim, os dados recolhidos por meio do protocolo de avaliação foram analisados e os resultados foram discutidos. 
Tabela 1 - Características dos cabos de segurança.

\begin{tabular}{|c|c|c|c|c|c|c|}
\hline Obra & $\begin{array}{l}\text { Etapa de } \\
\text { utilização }\end{array}$ & $\begin{array}{l}\text { Material } \\
\text { do cabo }\end{array}$ & $\begin{array}{l}\text { Fixação } \\
\text { do cabo }\end{array}$ & $\begin{array}{l}\text { Tipo de } \\
\text { montante }\end{array}$ & $\begin{array}{l}\text { Fixação do } \\
\text { montante }\end{array}$ & $\begin{array}{l}\text { Registro } \\
\text { fotográfico }\end{array}$ \\
\hline Obra A & Alvenaria & $\begin{array}{l}\text { Cabo } \\
\text { de fibra } \\
\text { sintética }\end{array}$ & $\begin{array}{l}\text { Transpassado } \\
\text { por aberturas } \\
\text { existentes } \\
\text { em pilares ou } \\
\text { vigas }\end{array}$ & $\begin{array}{l}\text { Pilares } \\
\text { e vigas } \\
\text { funcionam } \\
\text { como } \\
\text { montantes }\end{array}$ & $\begin{array}{l}\text { Pilares } \\
\text { e vigas } \\
\text { funcionam } \\
\text { como } \\
\text { montantes }\end{array}$ & \\
\hline Obra B & Estrutura & $\begin{array}{l}\text { Cabo de } \\
\text { aço }\end{array}$ & $\begin{array}{l}\text { Transpassado } \\
\text { em } \\
\text { abraçadeiras } \\
\text { presas ao } \\
\text { montante }\end{array}$ & $\begin{array}{l}\text { Tubos de } \\
\text { ferro }\end{array}$ & $\begin{array}{l}\text { Sustentação } \\
\text { em formato } \\
\text { de tripé } \\
\text { fixado à laje } \\
\text { por meio de } \\
\text { parafusos }\end{array}$ & \\
\hline Obra C & Alvenaria & $\begin{array}{l}\text { Cabo } \\
\text { de fibra } \\
\text { sintética }\end{array}$ & $\begin{array}{l}\text { Transpassado } \\
\text { em barras } \\
\text { de ferro com } \\
\text { dobra em sua } \\
\text { ponta }\end{array}$ & $\begin{array}{l}\text { Barras de } \\
\text { ferro }\end{array}$ & $\begin{array}{l}\text { A partir de } \\
\text { solda na laje } \\
\text { superior }\end{array}$ & \\
\hline Obra D & Alvenaria & $\begin{array}{l}\text { Cabo de } \\
\text { aço }\end{array}$ & $\begin{array}{l}\text { Transpassados } \\
\text { em aberturas } \\
\text { feitas a } 1,20 \\
\text { m de altura no } \\
\text { montante }\end{array}$ & $\begin{array}{l}\text { Tubos de } \\
\text { ferro com } \\
8 \mathrm{~m}\end{array}$ & $\begin{array}{l}\text { Sistema de } \\
\text { encaixe, } \\
\text { no qual os } \\
\text { cabos são } \\
\text { passados } \\
\text { em espaços } \\
\text { já deixados } \\
\text { na laje e } \\
\text { fixados } \\
\text { com pino } \\
\text { metálico }\end{array}$ & \\
\hline
\end{tabular}

Fonte: Elaboração dos autores. 
Tabela 1 - Continuação.

\begin{tabular}{|c|c|c|c|c|c|c|}
\hline Obra & $\begin{array}{l}\text { Etapa de } \\
\text { utilização }\end{array}$ & $\begin{array}{l}\text { Material } \\
\text { do cabo }\end{array}$ & $\begin{array}{l}\text { Fixação } \\
\text { do cabo }\end{array}$ & $\begin{array}{l}\text { Tipo de } \\
\text { montante }\end{array}$ & $\begin{array}{l}\text { Fixação do } \\
\text { montante }\end{array}$ & $\begin{array}{l}\text { Registro } \\
\text { fotográfico }\end{array}$ \\
\hline Obra E & Estrutura & $\begin{array}{l}\text { Cabo de } \\
\text { aço }\end{array}$ & $\begin{array}{l}\text { Transpassado } \\
\text { em } \\
\text { abraçadeiras } \\
\text { presas ao } \\
\text { montante }\end{array}$ & $\begin{array}{l}\text { Tubos de } \\
\text { ferro com } \\
6 \mathrm{~m}\end{array}$ & $\begin{array}{l}\text { Encaixados } \\
\text { através dos } \\
\text { espaços } \\
\text { deixados } \\
\text { entre as } \\
\text { lajes }\end{array}$ & \\
\hline Obra F & Estrutura & $\begin{array}{l}\text { Cabo de } \\
\text { aço }\end{array}$ & $\begin{array}{l}\text { Transpassado } \\
\text { em } \\
\text { abraçadeiras } \\
\text { presas ao } \\
\text { montante ou } \\
\text { em encaixe } \\
\text { fixo a } 1,5 \mathrm{~m} \text { de } \\
\text { altura }\end{array}$ & $\begin{array}{l}\text { Tubos de } \\
\text { ferro com } \\
7 \mathrm{~m}\end{array}$ & $\begin{array}{l}\text { Encaixados } \\
\text { através dos } \\
\text { espaços } \\
\text { deixados } \\
\text { entre as } \\
\text { lajes }\end{array}$ & 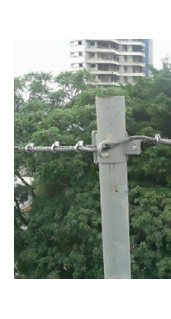 \\
\hline Obra G & Estrutura & $\begin{array}{l}\text { Cabo de } \\
\text { aço }\end{array}$ & $\begin{array}{l}\text { Transpassado } \\
\text { em } \\
\text { abraçadeiras } \\
\text { presas ao } \\
\text { montante }\end{array}$ & $\begin{array}{l}\text { Tubos de } \\
\text { ferro }\end{array}$ & $\begin{array}{l}\text { Possui } \\
\text { sustentação } \\
\text { de tripé e os } \\
\text { tubos são } \\
\text { encaixados } \\
\text { através dos } \\
\text { espaços } \\
\text { deixados } \\
\text { entre as } \\
\text { lajes }\end{array}$ & \\
\hline
\end{tabular}

Fonte: Elaboração dos autores.

\section{Resultados}

\subsection{Segurança nos Projetos dos Cabos}

A Tabela 2 apresenta os resultados da avaliação quanto aos requisitos concernentes à categoria segurança na fase de concepção dos projetos, a média de cada empresa, média de cada requisito e média geral da categoria. 
Tabela 2 - Atendimento da categoria segurança no projeto dos cabos.

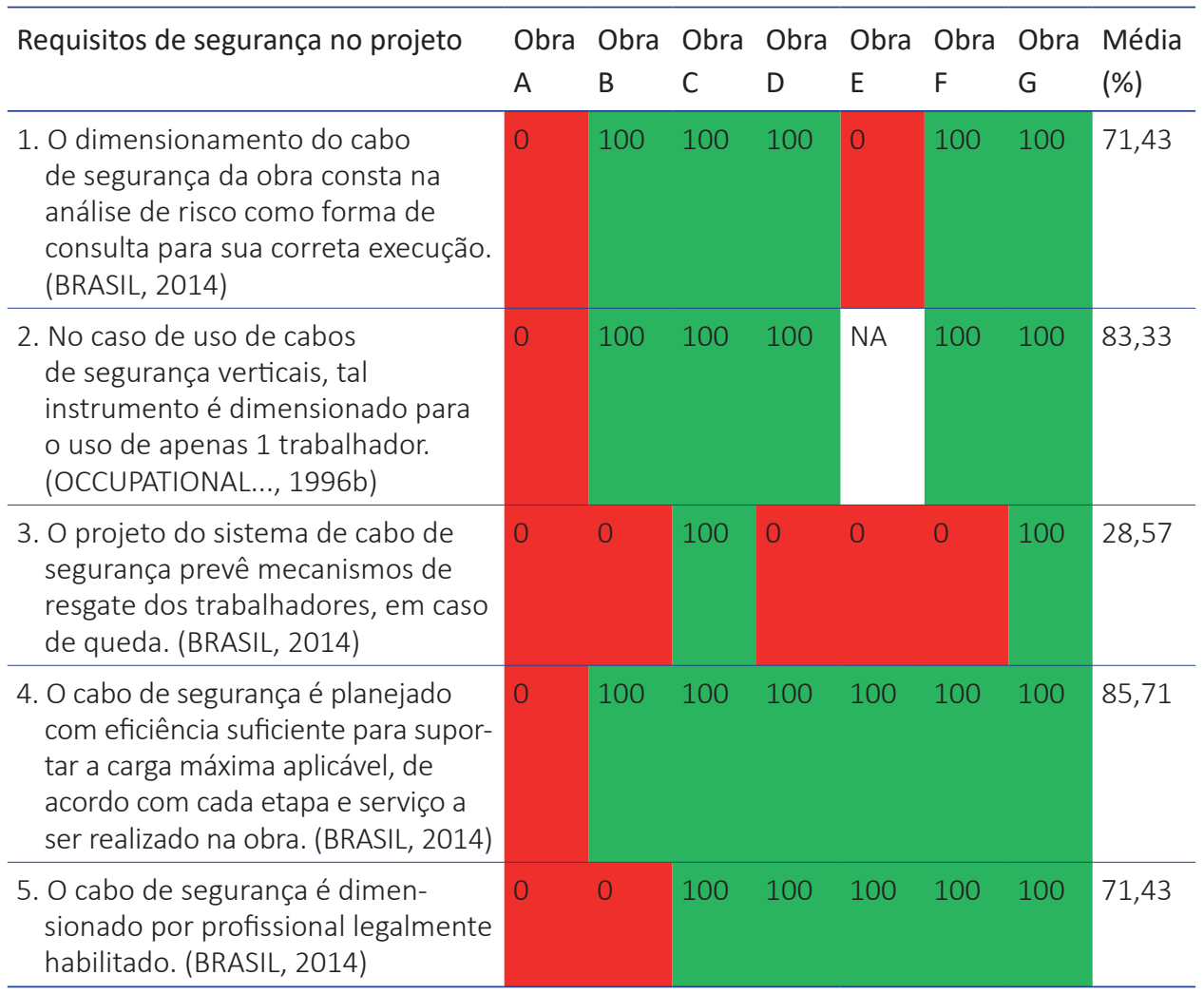

Fonte: Elaboração dos autores.

Percebe-se que a maioria das empresas preocupa-se em dimensionar seus sistemas seguindo as especificações de um profissional habilitado, que considera a análise de risco, as cargas e número real de usuários do sistema.

Em contrapartida, as porcentagens de atendimento do requisito 3 possibilitam identificar como inconformidade comum, entre a maioria das empresas, a não incorporação de formas de resgate ao dimensionamento dos cabos, visto que é obrigação da empresa assegurar que a equipe possua os recursos necessários para as respostas a emergências, conforme exige a NR 35 - Trabalho em Altura.

\subsection{Segurança na Fase de Operação}

A Tabela 3 apresenta os resultados de atendimento das obras quanto aos requisitos referentes à categoria segurança na fase de uso dos cabos, a média de cada empresa, média de cada requisito e média geral da categoria. 
Quanto à operação, o requisito de número 14 foi o menos atendido entre as obras, de modo que apenas a obra D possuía sinalização, no local de uso, informando a quantidade máxima de trabalhadores que podem estar conectados ao cabo de segurança ao mesmo tempo. Esse foi o requisito menos atendido dentre os 30 analisados.

Verifica-se que o não atendimento ao item 14 interfere no total desempenho quanto ao cumprimento dos requisitos 2 e 4 da categoria segurança na fase de projeto, pois mesmo que haja um correto dimensionamento da carga e número máximo de trabalhadores suportados pelo sistema, não é realizada a eficiente sinalização destas informações aos trabalhadores em obra, durante a etapa de operação dos cabos.

Tabela 3 - Atendimento da categoria segurança na fase de operação dos cabos.

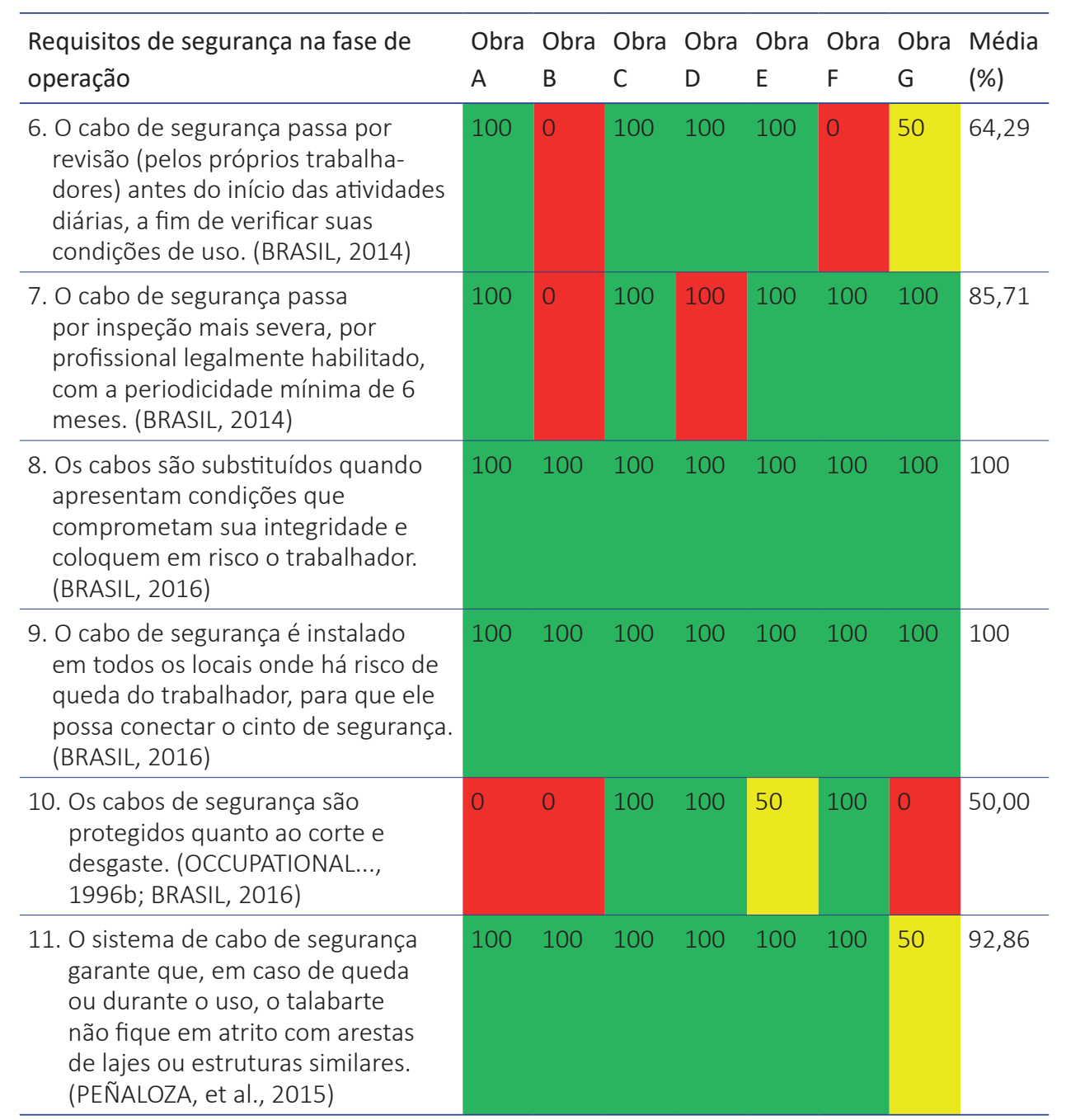

Fonte: Elaboração dos autores. 
Tabela 3 - Continuação.

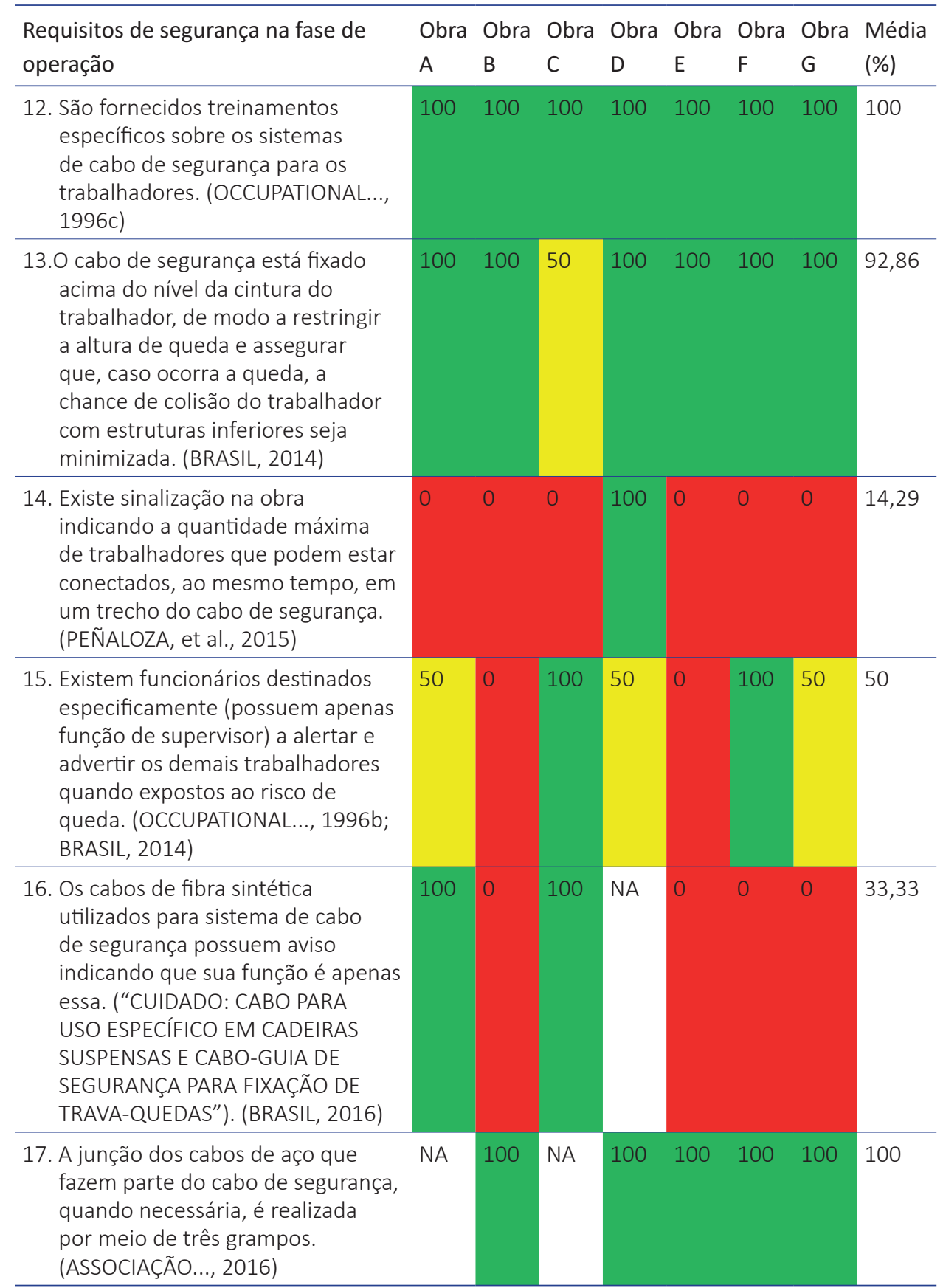

Fonte: Elaboração dos autores. 
Já os requisitos 8, 9, 12 e 17 são cumpridos em todas as obras. Assim, constatouse a preocupação das empresas em instalar cabos de segurança em todos os locais com risco de queda, de maneira a preservar a integridade do trabalhador e também oferecer treinamentos para capacitar seus funcionários.

\subsection{Categoria Eficiência}

A Tabela 4 apresenta os resultados de atendimento das obras quanto aos requisitos na categoria eficiência, a média de cada empresa, média de cada requisito e média geral da categoria.

Tabela 4 - Atendimento da categoria eficiência.

\begin{tabular}{|c|c|c|c|c|c|c|c|c|}
\hline Requisitos de eficiência & $\begin{array}{l}\text { Obra } \\
\text { A }\end{array}$ & $\begin{array}{l}\text { Obra } \\
\text { B }\end{array}$ & $\begin{array}{l}\text { Obra } \\
\text { C }\end{array}$ & $\begin{array}{l}\text { Obra } \\
\text { D }\end{array}$ & $\begin{array}{l}\text { Obra } \\
E\end{array}$ & $\begin{array}{l}\text { Obra } \\
\text { F }\end{array}$ & $\begin{array}{l}\text { Obra } \\
\text { G }\end{array}$ & $\begin{array}{l}\text { Média } \\
\text { (\%) }\end{array}$ \\
\hline $\begin{array}{l}\text { 18. O sistema de cabo de } \\
\text { segurança interfere } \\
\text { negativamente no } \\
\text { desenvolvimento do } \\
\text { serviço do trabalhador. } \\
\text { (OCCUPATIONAL..., 1996a) }\end{array}$ & 50 & 0 & 0 & 0 & 0 & 100 & 100 & 35,71 \\
\hline $\begin{array}{l}\text { 19. O sistema de cabo de } \\
\text { segurança garante ao } \\
\text { trabalhador autonomia para } \\
\text { realizar a atividade por todo } \\
\text { período que estiver exposto } \\
\text { ao risco de queda. (BRASIL, } \\
\text { 2014) }\end{array}$ & 50 & 100 & 100 & 100 & 100 & 100 & 100 & 92,86 \\
\hline $\begin{array}{l}\text { 20. O sistema de cabo de } \\
\text { segurança é de rápida } \\
\text { instalação e retirada. } \\
\text { (PEÑALOZA et al., 2015) }\end{array}$ & 50 & 0 & 50 & 50 & 0 & 100 & 50 & 42,86 \\
\hline $\begin{array}{l}\text { 21. O sistema de cabo de } \\
\text { segurança tem pouca ou } \\
\text { nenhuma interferência com } \\
\text { outras proteções coletivas } \\
\text { (proteções periféricas, } \\
\text { plataformas de proteção) } \\
\text { e escoramentos, não } \\
\text { prejudicando a segurança e } \\
\text { eficiência da movimentação } \\
\text { de materiais e pessoas. } \\
\text { (PEÑALOZA et al., 2015) }\end{array}$ & 50 & 100 & 100 & 50 & 50 & 100 & 100 & 78,57 \\
\hline
\end{tabular}

Fonte: Elaboração dos autores. 
Tabela 4 - Continuação.

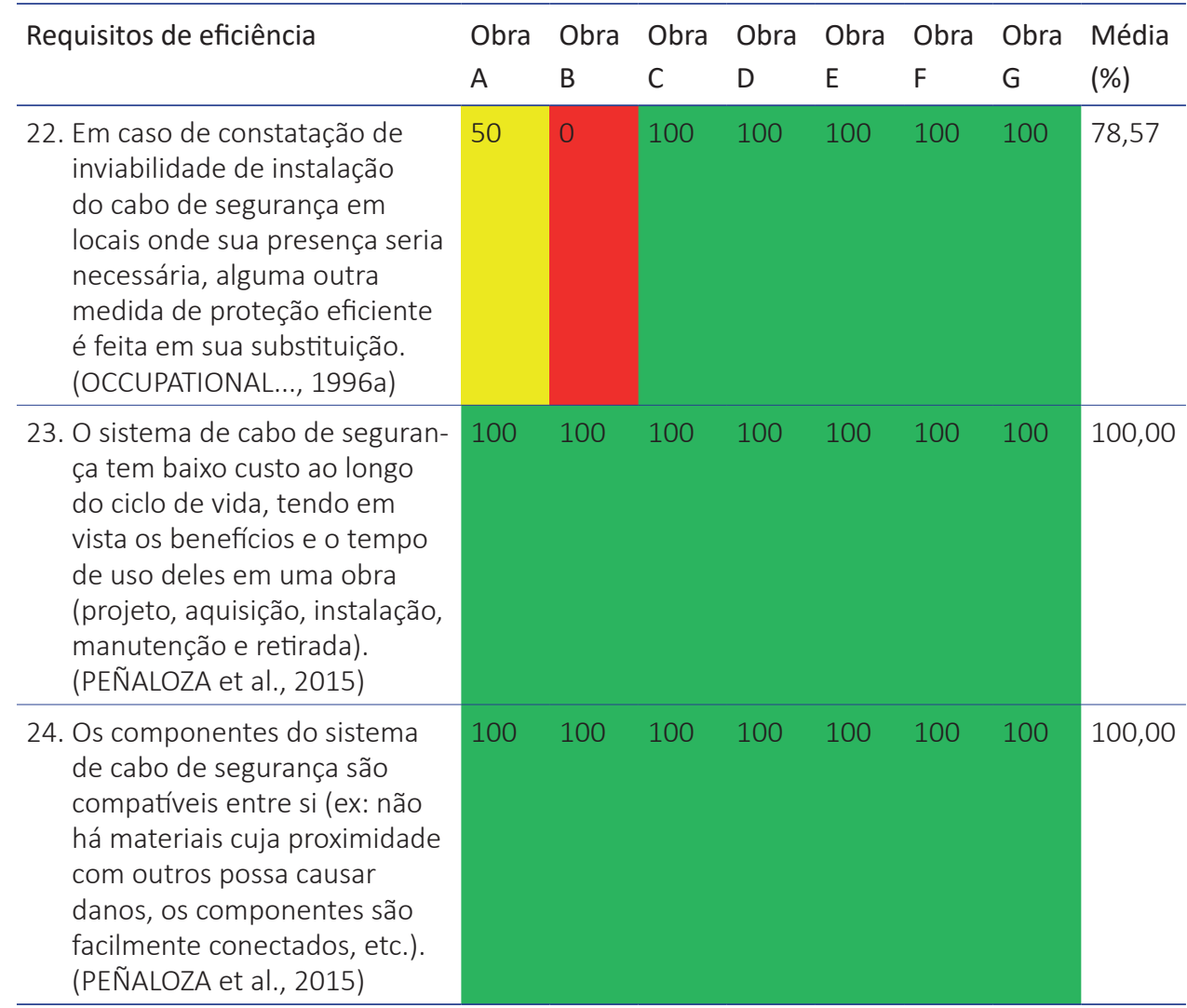

Fonte: Elaboração dos autores.

De acordo com a Tabela 4, os requisitos 23 e 24 obtiveram atendimento máximo, posto que todos os engenheiros entrevistados consideram o custo dos cabos de segurança baixo, tendo em vista seus benefícios ao longo do ciclo de vida. O requisito de número 18, atendido totalmente em duas obras e parcialmente em uma, obteve média de somente $35,71 \%$, pois a maioria dos engenheiros entrevistados considera que o cabo influencia negativamente no desenvolvimento das atividades, diminuindo a produtividade.

Analisando os requisitos 18 e 20 em conjunto, pode-se observar que há uma relação entre os sistemas não permitirem uma rápida instalação e retirada e a interferência negativa nos serviços dos trabalhadores. Esse fato se explica, dentre outros motivos, pela necessidade de repetidas retiradas e conexões do cinto de segurança por parte do trabalhador e pela grande variedade e número de sistemas existentes nos canteiros. 


\subsection{Categoria Flexibilidade}

A Tabela 5 apresenta os resultados de atendimento das obras quanto aos requisitos na categoria flexibilidade, a média de cada empresa, média de cada requisito e média geral da categoria. Nessa categoria, todos os itens superaram os $70 \%$ de atendimento, sendo o requisito 25 o mais atendido, pois todas as empresas possuíam sistemas que poderiam ser utilizados em todas as etapas da obra.

Tabela 5 - Atendimento da categoria flexibilidade.

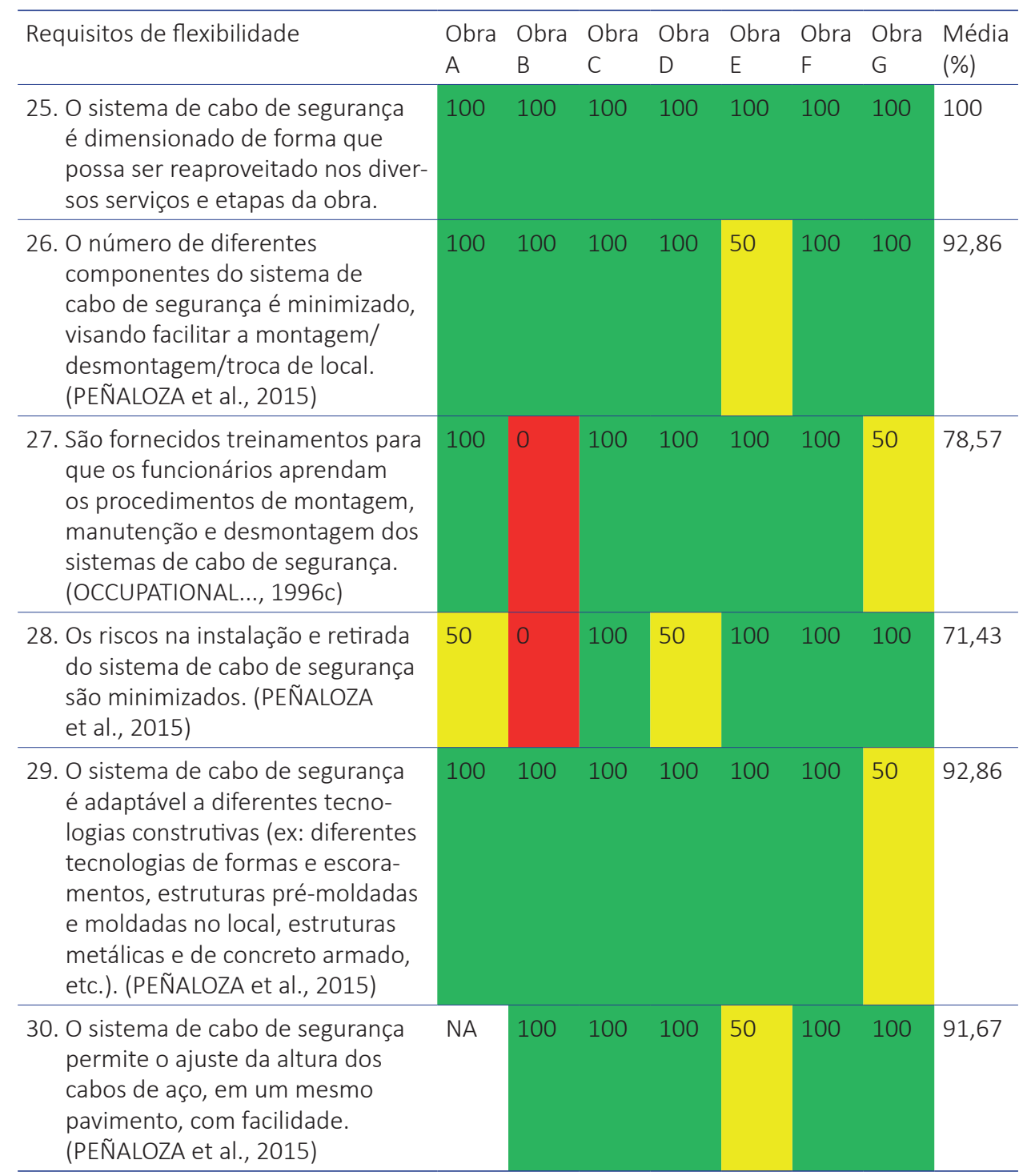

Fonte: Elaboração dos autores. 
Nessa categoria, sete requisitos obtiveram $100 \%$ de atendimento. Os principais fatos que levaram ao alcance destes resultados foram a relevância que as empresas deram ao dimensionamento envolvendo praticidades em montagem, utilização e desmontagem do sistema, além da análise efetiva das possibilidades de interferência entre os sistemas existentes nos canteiros.

A facilidade de desmontagem e a minimização de peças, abordada pelo projeto de dimensionamento, bem como o fornecimento de treinamentos aos trabalhadores, contribuíram com a possibilidade de uma reutilização eficiente dos cabos, nas diferentes etapas da obra ou em obras futuras, buscando dessa forma diminuir seu custo ao longo do ciclo de vida.

\subsection{Comparação de Atendimento entre as Categorias e entre as Obras}

Observando a Figura 1, pode-se perceber que a categoria flexibilidade foi a mais atendida, obtendo média de atendimento de $87,86 \%$. Já a categoria segurança nos projetos foi a que obteve menor atendimento entre as obras.

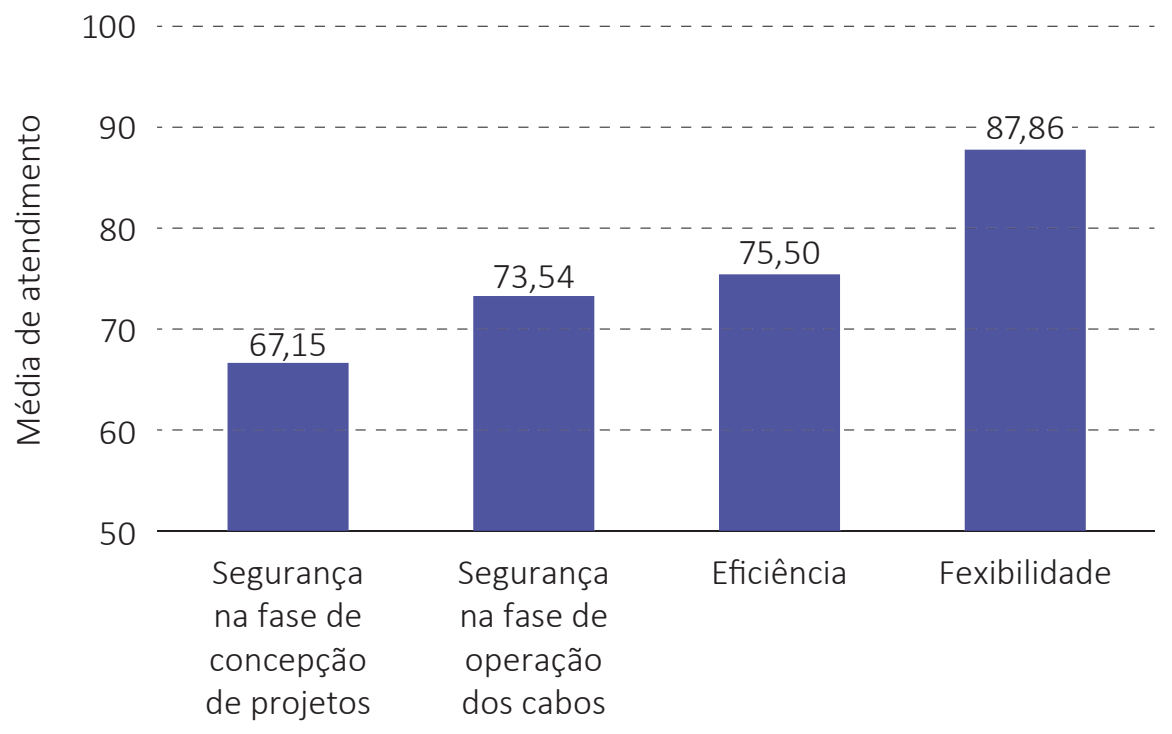

Categoria

Figura 1 - Média de atendimento das categorias. Fonte: Autores.

A Figura 2 permite observar as porcentagens de atendimento de cada uma das sete empresas analisadas, de maneira individual para cada categoria. Referente 
à primeira categoria, nota-se que as obras C e G obtiveram os melhores resultados com níveis máximos de atendimento aos requisitos de segurança na fase de projeto, sendo a obra $\mathrm{A}$ a responsável pelas piores porcentagens. Esta atingiu o resultado de $0 \%$ de atendimento devido ao fato de não realizar o dimensionamento por profissional habilitado e não apresentar grau de detalhamento adequado nos projetos fornecidos aos funcionários responsáveis pela montagem do sistema, os quais acabavam por efetuar de maneira empírica.

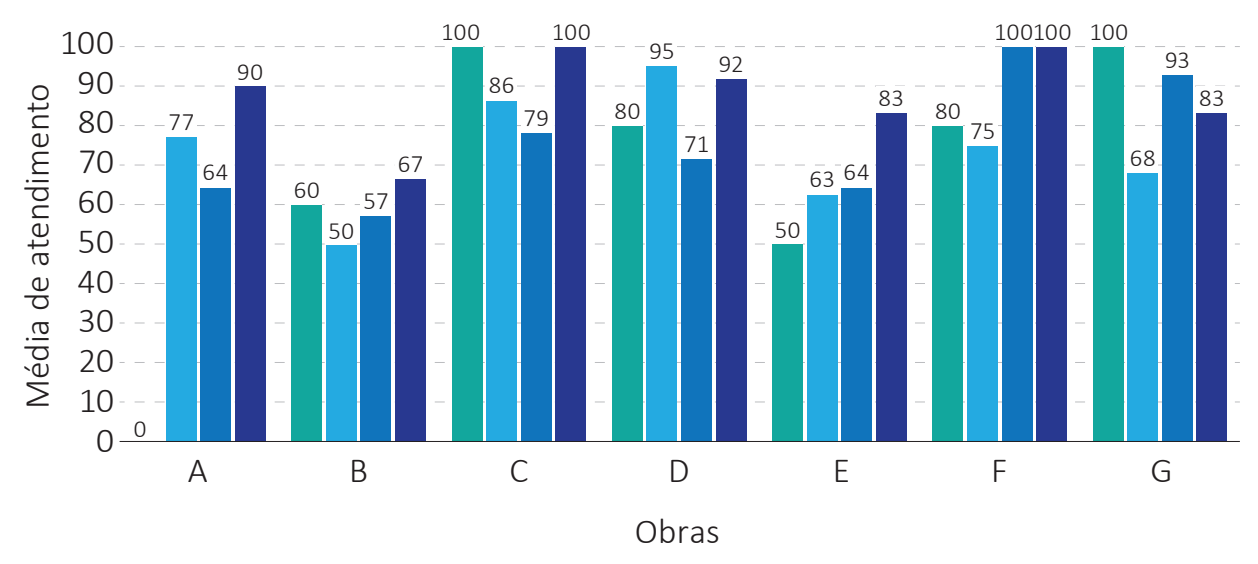

Segurança na fase de concepção de projetos

- Segurança na fase de operação dos cabos

Eficiência

- Flexibilidade

Figura 2 - Média total de atendimento por cada obra. Fonte: Autores.

Quanto à categoria "Segurança na fase de operação dos cabos", foram obtidos os melhores resultados na obra $D$, a qual atingiu $95,45 \%$ de cumprimento aos requisitos. O pior desempenho nessa categoria foi apresentado pela obra B, uma vez que pontos importantíssimos à aplicação segura do sistema foram descumpridos, como revisões, inspeções e sinalizações aos usuários.

A categoria "Eficiência" teve a obra F como a de melhor desempenho com $100 \%$ dos requisitos atendidos. Esta se preocupava em garantir um fácil manuseio e utilização do sistema mediante o emprego de montantes, cabos reutilizados de andaimes e ajuste de altura a partir de abraçadeira, conforme Figura 3. Salienta-se ainda a compatibilidade entre os componentes, sem que houvesse interferência entre o cabo de segurança e outros equipamentos instalados em obra. Novamente, nessa categoria, a obra B obteve o pior desempenho, pois o sistema não proporcionava rapidez na instalação e retirada, interferia de maneira negativa na produtividade dos 
trabalhadores e não previa outro meio de proteção para casos de inviabilidade de instalação do cabo.

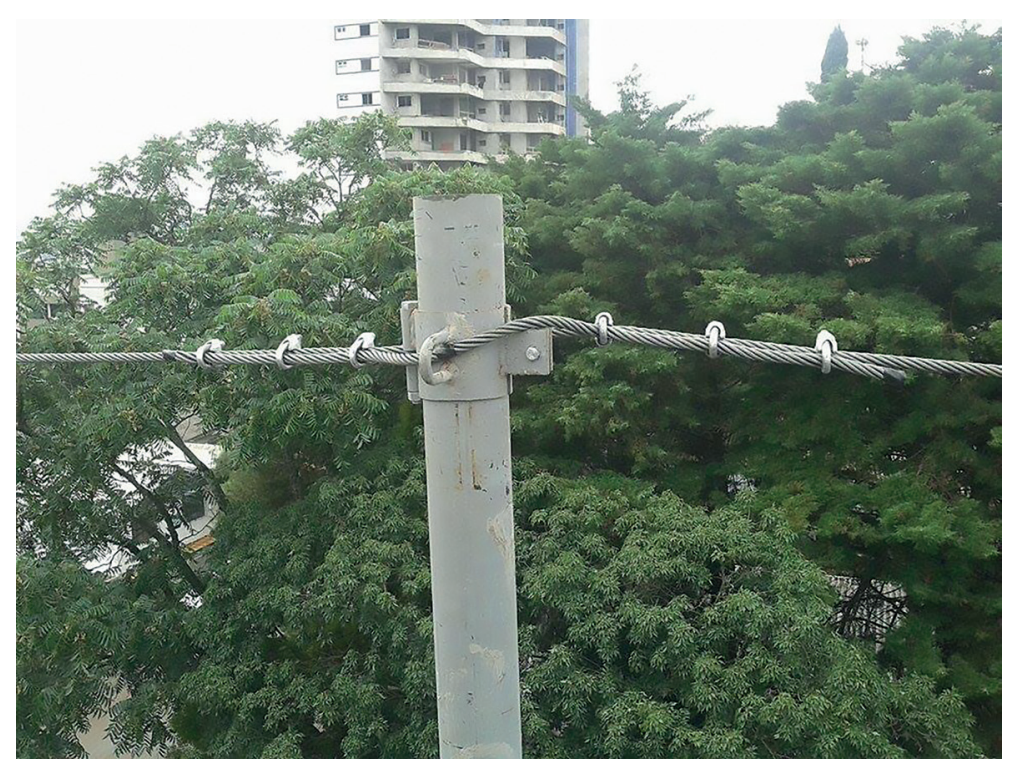

Figura 3 - Montantes, cabos de aço e abraçadeiras na obra F. Fonte: Autores.

A última categoria analisada foi "Flexibilidade", na qual duas obras obtiveram o mesmo desempenho, com $100 \%$ dos requisitos atendidos, sendo elas as obras $\mathrm{C}$ e F. Além destas, pode-se citar como referência de bom resultado a obra $D$, que obteve 91,67\% de atendimento, com apenas um requisito sem atingir total conformidade.

Em relação a desempenho negativo, essa foi a terceira categoria em que a obra B atingiu os piores resultados, apresentando 66,67\% de atendimento, uma vez que não era disponibilizado treinamento aos trabalhadores nem, em nenhum momento da instalação do sistema, buscava-se minimizar os riscos de queda aos envolvidos.

Avaliando os resultados por categoria, destacam-se as obras B, C e F. A obra B obteve os piores resultados em três das quatro categorias analisadas, e as obras $\mathrm{C}$ e $\mathrm{F}$ atingiram o melhor desempenho dentre todas as sete obras.

\section{Conclusões}

Ainda que a utilização de equipamentos de segurança contra quedas seja crescente na busca por índices menores de acidentes, métodos que permitam avaliar seu uso como meio de aplicar melhorias e de atingir maiores conformidades com requisitos normativos e de natureza prática são necessários. 
Realizou-se, desta forma, a aplicação de um protocolo de avaliação em obra, que incorporou tanto os requisitos de normas, quanto os originados a partir de vivência em canteiros, sendo classificados dentro das categorias "Segurança", na etapa de projeto e operação, "Eficiência" e "Flexibilidade".

Como principais resultados, salienta-se a categoria "Segurança na fase de concepção de projetos" como a de menor desempenho e a "Flexibilidade" como a mais atendida. Pode-se assim aferir que a maioria das empresas não valoriza um projeto e planejamento eficazes como principais certificadores das condições de segurança adequada aos trabalhadores e até mesmo do aumento do rendimento desses atores da construção civil. Além do mais, conclui-se que maiores esforços concentram-se em cumprir os requisitos que envolvam a redução de custos, como a possibilidade de reutilização e adaptação do equipamento a diferentes arranjos e obras.

Já os cabos de fibra sintética transpassados em barras de ferro com uma dobra em sua ponta, utilizado pela obra $\mathrm{C}$ durante a etapa de levantamento de alvenaria, apresentou o maior desempenho, sendo possível apontar a presença e exercício constante do técnico e engenheiro de segurança do trabalho no canteiro de obras como promotores deste resultado. Tais profissionais realizavam o planejamento semanal das atividades em altura e controle dos trabalhos por meio de registro de Permissão para Trabalho (PT).

Além disso, pode-se concluir que o projeto de dimensionamento era efetuado de modo a cumprir com requisitos de segurança para cabos em fibra sintética, como os estabelecidos pela NR 18 - Condições e meio ambiente de trabalho na indústria da construção, em seu item 18.16 e Anexo I, comprovado pelos 100\% de atendimento à categoria segurança na fase de projeto.

Especificamente à avaliação das categorias e seus requisitos, todos os resultados ressaltam a importância de aplicar o método de avaliação proposto no estudo como ferramenta às empresas na análise dos processos utilizados na concepção, uso e manuseio de seus cabos de segurança.

\section{Referências}

ASSOCIAÇÃO BRASILEIRA DE NORMAS TÉCNICAS. NBR 11.900-4: Terminal para cabo de aço. Parte 4: Grampos leve e pesado. Rio de Janeiro, 2016.

BORJAN, M.; PATEL, T.; LEFKOWITZ, D.; CAMPBELL, C.; LUMIA, M. Assessing barriers to the use of fall protection in small residential construction companies in New Jersey. New solutions: a journal of environmental and occupational health policy, v. 26, n. 1, p. 40-54, 2016. 
BRANCHTEIN, M.C.; SOUZA, G.L.; SIMON, W.R. Sistema de proteção ativa contra quedas com Linha de Vida Horizontal Flexível. In: FILGUEIRAS, V. A. (Org.). Sergipe: Procuradoria Regional do Trabalho da $20^{\circ}$ região, 2015. p. 159-176.

BRASIL. Ministério do Trabalho e Emprego. Norma Regulamentadora 18 (NR-18): Condições e meio ambiente de trabalho na indústria da construção. 2015. Brasília-DF. Disponível em: <http://trabalho.gov.br/seguranca-e-saude-no-trabalho/normatizacao/ normas-regulamentadoras/norma-regulamentadora-n-18-condicoes-e-meio-ambientede-trabalho-na-industria-da-construcao>. Acesso em: nov. 2016.

BRASIL. Ministério do Trabalho e Emprego. Norma Regulamentadora 35 (NR-35): Trabalho em Altura. Rio de Janeiro: 2014. Disponível em: <http://portal.mte.gov.br/images/ Documentos/SST/NR/NR4.pdf>. Acesso em: nov. 2015.

CHERRI, S.; ARGUDIN, R. Fall rescue plans \& dropped object prevention: what every safety manager should know. Professional Safety, v. 61, n. 5, p. 38-41, 2016.

EVANOFF, B.; DALE, A.M.; ZERINGUE, A.; FUCHS, M.; GAAL, J.; LIPSCOMB, H.J.; KASKUTAS, $V$. Results of a fall prevention educational intervention for residential construction. Safety Science, v. 89, n. 9, p. 301-307, 2016.

OCCUPATIONAL SAFETY AND HEALTH ADMINISTRATION. United States Department of Labour. 1926.501 - Duty to have fall protection. 1996a. Disponível em: https://www.osha. gov/pls/oshaweb/owadisp.show_document?p_table=STANDARDS\&p_id=10757. Acesso em: set. 2015.

OCCUPATIONAL SAFETY AND HEALTH ADMINISTRATION. United States Department of Labour. 1926.502 - Fall protection systems criteria and practices. 1996b. Disponível em: https://www.osha.gov/pls/oshaweb/owadisp.show_document?p_table=STANDARDS\&p_ id=10758 Acesso em: set. 2015.

OCCUPATIONAL SAFETY AND HEALTH ADMINISTRATION. United States Department of Labour. 1926.503 - Training requirements. 1996c. Disponível em: https://www.osha.gov/ pls/oshaweb/owadisp.show_document?p_table=STANDARDS\&p_id=10759 Acesso em: set. 2015.

PEÑALOZA, G.A.; FORMOSO, C.T.; SAURIN, T.A. Avaliação de requisitos de desempenho de Sistemas de Proteção Periférica (SPP). Ambiente Construído, Porto Alegre, v. 15, n. 4, p. 267-289, out./dez. 2015. 